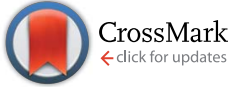

Cite this: RSC Adv., 2017, 7, 4872

Received 21st November 2016 Accepted 3rd January 2017

DOI: $10.1039 / c 6 r a 27069 g$

www.rsc.org/advances

\section{Synthesis of homochiral zeolitic metal-organic frameworks with amino acid and tetrazolates for chiral recognition $\uparrow$}

\author{
Min-Yu Li, Fei Wang, * Zhi-Gang Gu and Jian Zhang* \\ By mixing amino acids and tetrazolate ligands, a series of homochiral zeolitic metal-organic frameworks \\ (ZMOFs) with ABW topology have been synthesized, and these materials show permanent microporosity \\ and potential enantioselective recognition ability.
}

\section{Introduction}

Within the last few years, inorganic zeolites and zeolitic metalorganic frameworks (ZMOFs) have received much attention due to their fascinating tetrahedral structures, high stability, and tailored functionalities..$^{1-5}$ Among them, the combination of the tetrahedrally coordinated divalent cations $\left(\mathrm{M}^{2+}=\mathrm{Zn}^{2+}\right.$ or $\left.\mathrm{Co}^{2+}\right)$ and uninegative azolate ligands (especially imidazolate and tetrazolate derivatives) results in the successful development of zeolitic imidazolate frameworks (ZIFs) and tetrahedral tetrazolate frameworks (TTFs). ${ }^{4-7}$ TTFs $^{7}$ possess uncoordinated N-heteroatom sites from the $\mu_{2}$-tetrazole ligands, and show promising potential applications in carbon dioxide capture and separation.

As enantioselective separation of racemates is especially important for the chemical and pharmaceutical industries, homochiral MOFs with such a function have attracted a great deal of attention in recent years. ${ }^{8,9}$ The most reliable approach to prepare homochiral MOFs is to select a enantiopure ligand as the primary linker to impart homochirality to the framework. The natural amino acids are ideal candidates because of their low cost and strong coordination ability. So far, although tremendous efforts have been devoted to the design and synthesis of novel homochiral MOFs based on optically pure amino acids and their derivatives, ${ }^{10,11}$ it remains highly challenging to construct homochiral MOFs with zeolitic topology. Recently, we have developed one kind of homochiral ZMOFs based on enantiopure amino acids ligand. ${ }^{11}$ By choosing a pair of enantiopure amino acids (L-Alanine and D-Alanine) as linkers and octahedral Ni(II) metal centers as 4-connected nodes, two homochiral MOFs with SOD topology are successfully synthesized. However, the short $\mathrm{Ni} \cdots \mathrm{Ni}$ distance made it a dense framework without pore.

State Key Laboratory of Structural Chemistry, Fujian Institute of Research on the Structure of Matter, Chinese Academy of Sciences, Fuzhou, Fujian 350002, P. R. China.E-mail:wangfei04@fjirsm.ac.cn; zhj@fjirsm.ac.cn

$\dagger$ Electronic supplementary information (ESI) available: TGA, PXRD, and additional figures. CCDC 1511625-1511628. For ESI and crystallographic data in CIF or other electronic format see DOI: 10.1039/c6ra27069g
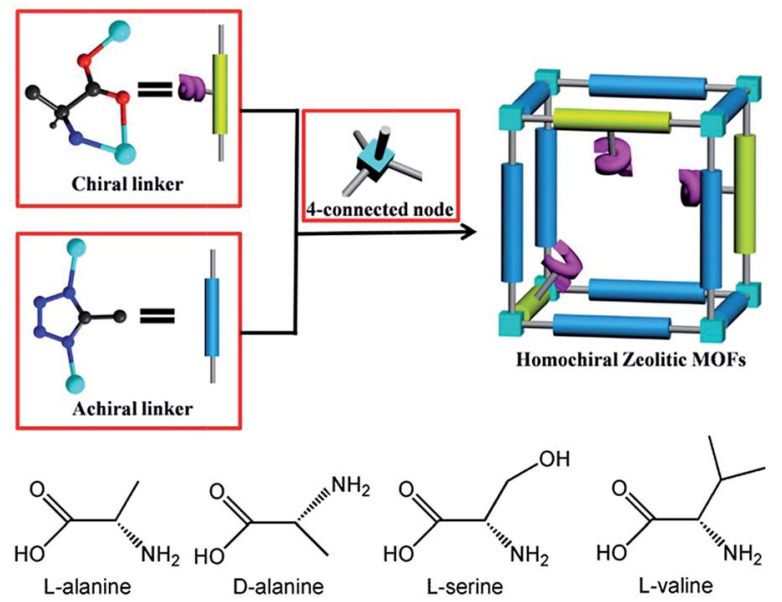

Scheme 1 The synthesis strategy of the homochiral ZMOFs.

In this work, we report a new approach to construct microporous homochiral ZMOFs based on enantiopure amino acids and tetrazolate derivatives. We select four enantiopure amino acids (L-lanine (L-Ala)), D-lanine (D-Ala), L-serine (L-Ser), and ( $\mathrm{L}-$ valine $(\mathrm{L}-\mathrm{Val})$ ) in combination with 5 -methyltetrazole $(5-\mathrm{Hmtz})$ ligand (Scheme 1) to realize four homochiral ZMOFs $\mathrm{Zn}_{4}(5-$ $\mathrm{mtz})_{6}(\mathrm{~L}-\mathrm{Ala})_{2} \cdot 2(\mathrm{DMF}) \quad(\mathbf{1 L}), \mathrm{Zn}_{4}(5-\mathrm{mtz})_{6}(\mathrm{D}-\mathrm{Ala})_{2} \cdot 2(\mathrm{DMF})$ (1D), $\mathrm{Zn}_{4}(5-\mathrm{mtz})_{6}(\mathrm{~L}-\mathrm{Ser})_{2} \cdot 2(\mathrm{DMF})(2 \mathrm{~L})$ and $\mathrm{Zn}_{4}(5-\mathrm{mtz})_{6}(\mathrm{~L}-\mathrm{Val})_{2} \cdot 2(\mathrm{DMF})$ (3L) with ABW topology for the first time. Furthermore, these materials show permanent microporosity and enantioselective recognition ability.

\section{Experimental}

\section{Measurements}

Elemental analyses of $\mathrm{C}, \mathrm{H}$ and $\mathrm{N}$ were measured on a Vario MICRO E III elemental analyzer. The IR spectra ( $\mathrm{KBr}$ pellets) were recorded on a Magna 750 FT-IR spectrophotometer. Powder X-ray diffraction data were recorded on a Rigaku 
MultiFlex diffractometer with a scan speed of $5^{\circ} \mathrm{min}^{-1}$. Thermal stability studies were carried out on a NETSCHZ STA449C thermoanalyzer under $\mathrm{N}_{2}$ (room temperature-600 ${ }^{\circ} \mathrm{C}$ range) at a heating rate of $10{ }^{\circ} \mathrm{C} \mathrm{min}^{-1}$. The gases adsorption isotherms were measured by using ASAP-2020 volumetric adsorption equipment. Circular dichroism (CD) experiments were recorded with a Bio-logic MOS-450 CD Spectrometer at room temperature.

\section{Synthesis}

Colorless crystals of $\mathbf{1 L}$ were solvothermally synthesized by the self-assembly of $\mathrm{Zn}\left(\mathrm{NO}_{3}\right)_{2} \cdot 6 \mathrm{H}_{2} \mathrm{O}, 5-\mathrm{Hmtz}$ and L-alanine in DMF solvent. 1D, 2L and 3L were obtained by using D-alanine, $\mathrm{L}^{-}$ serine, and L-valine respectively to replace the $\mathrm{L}$-alanine under the similar condition. The details of the synthesis of $1 \mathbf{L}, \mathbf{1 D}, \mathbf{2 L}$ and $\mathbf{3 L}$ were described in the ESI. $\dagger$

\section{Crystallography}

Crystallographic data of 1L, 1D and 2L were collected on a Mercury single crystal diffractometer equipped with graphitemonochromatic Mo $\mathrm{K} \alpha$ radiation $(\lambda=0.71073 \AA)$ at room temperature. Crystallographic data of $\mathbf{3} \mathbf{L}$ was collected on a SuperNova $(\mathrm{Cu})$ single crystal diffractometer equipped with graphite-monochromatic $\mathrm{Cu} \mathrm{K} \alpha$ radiation $(\lambda=1.54184 \AA)$ at room temperature. The structures were solved by direct methods and refined by full-matrix least-squares on $F^{2}$. All the structures were solved by using the program package SHELX2014/7. ${ }^{12}$ Non-hydrogen atoms were refined anisotropically, and all hydrogen atoms bond $\mathrm{C}$ were generated geometrically. Crystallographic data and structural refinement details for $\mathbf{1 L}$, 1D, 2L and 3L are listed in Table 1 . The starting amino acids are not optically pure, resulting in the high Flack values. ${ }^{13}$ CCDC 1511625 (1D), 1511626 (2L), 1511627 (1L) and 1511628 (3L) contain the ESI $\uparrow$ crystallographic data for this paper.

\section{Results and discussion}

\section{Structural description}

Single crystal X-ray analysis revealed that four compounds are isostructural. Here, only the structure of $\mathbf{1 L}$ is described in detail. 1L crystallizes in the monoclinic system with chiral space group $P 2_{1}$. The asymmetric unit of $\mathbf{1 L}$ consists of four $\mathrm{Zn}$ (II) ions, six 5-mtz, two L-Ala anions and two ordered DMF molecules. There are two kinds of $\mathrm{Zn}$ centers (Fig. 1a). One is tetrahedrally coordinated by three $\mathrm{N}$ atoms from three 5-mtz and one carboxylate oxygen atom from L-Ala. The other one shows a distorted trigonal bipyramidal configuration with fivecoordination, in which two $\mathrm{N}$ atoms from two 5-mtz and one amino $\mathrm{N}$ atom from $\mathrm{L}$-Ala occupy the three equatorial, and two axial positions are occupied by one $\mathrm{N}$ atom from one 5-mtz and one carboxylate oxygen atom from $\mathrm{L}-\mathrm{Ala}$. The $\mathrm{Zn}-\mathrm{O}$ bond lengths range from 1.947 to $2.305 \AA$. The $\mathrm{Zn}-\mathrm{N}$ bond lengths range from

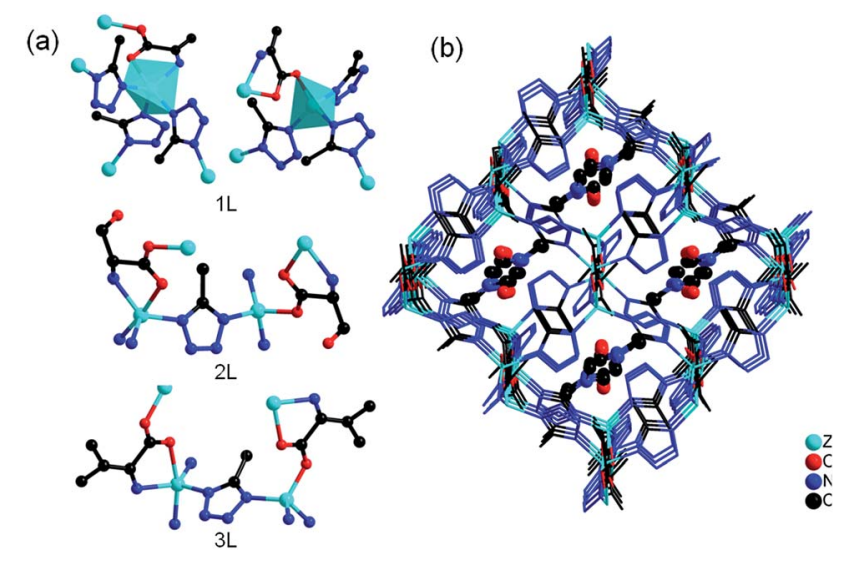

Fig. 1 (a) The coordination environment of metal centers in $1 \mathrm{~L}, 2 \mathrm{~L}$ and 3L; (b) the 3D framework of $1 \mathrm{~L}$ with guest molecule DMF (ball and stick) in the pores.

Table 1 Crystallographic data and structural refinement details for $1 \mathrm{~L}, 1 \mathrm{D}, 2 \mathrm{~L}$ and $3 \mathrm{~L}$

\begin{tabular}{|c|c|c|c|c|}
\hline & 1L & 1D & $2 \mathbf{L}$ & $3 \mathbf{L}$ \\
\hline Formula & $\mathrm{C}_{24} \mathrm{H}_{46} \mathrm{~N}_{28} \mathrm{O}_{7} \mathrm{Zn}_{4}$ & $\mathrm{C}_{24} \mathrm{H}_{46} \mathrm{~N}_{28} \mathrm{O}_{7} \mathrm{Zn}_{4}$ & $\mathrm{C}_{24} \mathrm{H}_{44} \mathrm{~N}_{28} \mathrm{O}_{8} \mathrm{Zn}_{4}$ & $\mathrm{C}_{28} \mathrm{H}_{52} \mathrm{~N}_{28} \mathrm{O}_{6} \mathrm{Zn}_{4}$ \\
\hline Formula weight & 1100.45 & 1100.45 & 1114.43 & 1138.54 \\
\hline$T / \mathrm{K}$ & $293(2)$ & $293(2)$ & $293(2)$ & $293(2)$ \\
\hline Crystal system & Monoclinic & Monoclinic & Monoclinic & Monoclinic \\
\hline Space group & $P 2_{1}$ & $P 2_{1}$ & $P 2_{1}$ & $P 2_{1}$ \\
\hline$a / \AA$ & $10.185(4)$ & $10.175(4)$ & $10.110(5)$ & $10.2303(3)$ \\
\hline$b / \AA$ & $21.488(9)$ & $21.481(10)$ & $21.362(10)$ & $21.4402(6)$ \\
\hline$c / \AA$ & $10.501(5)$ & $10.493(5)$ & $10.475(5)$ & $11.1573(4)$ \\
\hline$\alpha /^{\circ}$ & 90 & 90 & 90 & 90 \\
\hline$\beta /^{\circ}$ & $93.174(8)$ & $93.144(9)$ & $93.970(6)$ & $91.259(3)$ \\
\hline$\gamma /{ }^{\circ}$ & 90 & 90 & 90 & 90 \\
\hline$V / \AA^{3}$ & $2294.7(17)$ & $2290.0(18)$ & $2256.8(19)$ & $2446.65(13)$ \\
\hline$Z$ & 2 & 2 & 2 & 2 \\
\hline$D_{\text {calc }} / \mathrm{g} \mathrm{cm}^{-3}$ & 1.593 & 1.596 & 1.640 & 1.546 \\
\hline$\mu / \mathrm{mm}^{-1}$ & 2.137 & 2.142 & 2.176 & 2.810 \\
\hline$F(000)$ & 1124.0 & 1124.0 & 1136.0 & 1168.0 \\
\hline$R_{1}$ & 0.0643 & 0.0685 & 0.0733 & 0.0446 \\
\hline $\mathrm{w} R\left(F^{2}\right)$ & 0.1538 & 0.1590 & 0.1810 & 0.1304 \\
\hline GOF & 0.965 & 1.046 & 1.019 & 1.017 \\
\hline Flack & $0.24(5)$ & $0.33(5)$ & $0.21(5)$ & $0.17(7)$ \\
\hline
\end{tabular}


1.972 to $2.118 \AA$, respectively. The L-Ala ligand is coordinated to two $\mathrm{Zn}$ centers. All the 5-mtz ligands adopt similar coordination mode of 2-methylimidazole, using two $\mathrm{N}$ atoms to coordinate two $\mathrm{Zn}$ atoms. The $\mathrm{Zn} \cdots \mathrm{Zn}$ distances linked by 5 -mtz ligands range from 6.036 to $6.227 \AA$. In comparison, short $\mathrm{Zn} \cdots \mathrm{Zn}$ distances linked by L-Ala ligands ranging from 5.189 to $5.199 \AA$ are observed. All the $\mathrm{Zn}$ atoms were linked by 5-mtz ligands to form a layer (Fig. 2c), which can be simplified as a 3-connected $\left(6^{3}\right)$ net. The L-Ala ligands further link adjacent layers to form a 3D framework (Fig. 1b). Notably, a remarkably structural feature in $\mathbf{1 L}$ is the presence of three-dimensional 4-connected ABW network. As mentioned above, both of the L-Ala and 5-mtz act as $\mu_{2}$-bridging ligands. Each $\mathrm{Zn}$ center can be successfully reduced as a 4-connected node. As a result, the whole framework can be topologically represented as a uninodal 4-connected zeotype ABW topology by considering L-Ala and 5-mtz as simple linkers (Fig. 2a and d). Two kinds of channels along the $a$-axis are observed in the structure of $\mathbf{1 L}$. The small channel is from the typical double zigzag chain (DZC) which is well known in zeolite structures (Fig. 2b). The large channel with dimension of ca. $5.5 \times 11.2 \AA$ are filled by the structurally ordered DMF molecules. Strong $\mathrm{N}-\mathrm{H} \cdots \mathrm{O}$ hydrogen bonding interactions $\left(d_{\mathrm{N}-}\right.$ $\mathrm{o}=2.753 \AA$ and $2.945 \AA$ ) are observed between the amino ligand and the DMF guest (Fig. 1b). The solvent-accessible volume of ca. $32.1 \%$ was calculated by the PLATON program. ${ }^{14}$ The solvent-accessible volume for $\mathbf{2 L}$ and $\mathbf{3 L}$ were $\sim 30.7 \%$ and $\sim 30.1 \%$, respectively.

\section{X-ray powder diffraction and thermal analysis}

The powder X-ray diffraction patterns confirm the phase purity of the bulk products and also demonstrate that activated frameworks of 1L, 1D, 2L, 3L remain unchanged after gas sorption measurements (Fig. S1 $\dagger$ ). Thermal gravimetric analysis (TGA) shows that $\mathbf{1 L}, \mathbf{1 D}, \mathbf{2 L}, \mathbf{3 L}$ can be stable up to $c a .230^{\circ} \mathrm{C}$ under the $\mathrm{N}_{2}$ atmosphere (Fig. $\mathrm{S} 2 \dagger$ ).

\section{Gas absorption measurement}

Gas-adsorption measurements of $\mathbf{1 L}$ to $\mathbf{3} \mathbf{L}$ were performed on a Micromeritics ASAP 2020 surface-area and pore-size analyzer. The samples were activated by solvent exchange with ethanol followed by evacuation at $60{ }^{\circ} \mathrm{C}$ for 5 hours. The permanent

(a)

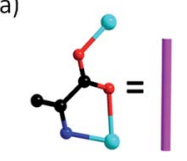

(c)

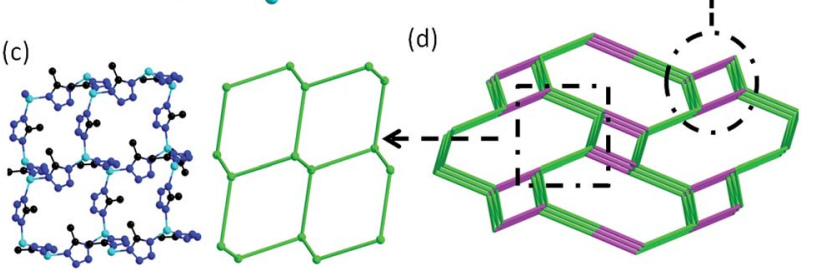

Fig. 2 (a) The simplified L-alanine and 5-methyltetrazole; (b) the DZC chain in 1L; (c) 3-connected net in $1 \mathrm{~L}$; (d) the ABW topology of $1 \mathrm{~L}$.
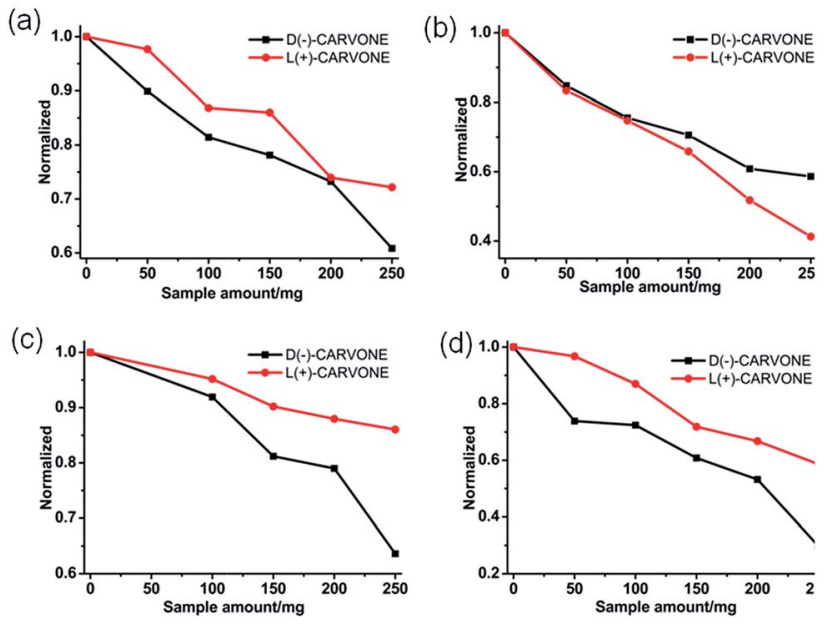

Fig. 3 Enantioselective recognition of carvone in ethanol solutions, (a) $1 \mathrm{~L} ;$ (b) $1 \mathrm{D}$; (c) $2 \mathrm{~L}$; (d) $3 \mathrm{~L}$.

porosity of $1 \mathrm{~L}$ to $3 \mathrm{~L}$ was confirmed by the reversible $\mathrm{CO}_{2}$ sorption measurements at $195 \mathrm{~K}$ (Fig. S3 $\dagger$ ). The Langmuir and BET surface areas of $1 \mathrm{~L}$ were $302 \mathrm{~m}^{2} \mathrm{~g}^{-1}$ and $294 \mathrm{~m}^{2} \mathrm{~g}^{-1}$, respectively. The Langmuir and BET surface areas for $2 \mathbf{L}$ were $377 \mathrm{~m}^{2}$ $\mathrm{g}^{-1}$ and $364 \mathrm{~m}^{2} \mathrm{~g}^{-1}$, respectively. 3L has the largest Langmuir and BET surface areas $\left(672 \mathrm{~m}^{2} \mathrm{~g}^{-1}\right.$ and $658 \mathrm{~m}^{2} \mathrm{~g}^{-1}$, respectively), which may be assigned to the isopropyl group connected to $\alpha$-C of amino acid enlarge the channel (Fig. 1).

\section{Chiral recognition of carvone}

Since 1L, 1D, 2L and 3L are homochiral frameworks, we are interested in their potential properties on chiral recognition of carvone. A solution of $\mathrm{D}$-carvone or L-carvone in ethanol with the same concentration $\left(10^{-2} \mathrm{~mol} \mathrm{~L}^{-1}\right)$ and amount $(2 \mathrm{~mL})$ were placed in the cells. Then the same amounts of the assynthesized samples of $\mathbf{1 L}, \mathbf{1 D}, \mathbf{2 L}$ and $3 \mathbf{L}$ were added respectively, and the circular dichroism (CD) signal was recorded. For 1L, 2L and 3L (Fig. 3a, c and d), the CD intensities of solutions decreased with the increased samples, however, the intensity of D-carvone decreased more drastically than that of L-carvone. The result means that the interactions between the samples based on L-amino and D-carvone are stronger than the interactions between the samples based on L-amino and L-carvone. For 1D (Fig. 3b), the intensity of L-carvone decreased more drastically than that of D-carvone, which indicates the stronger interactions between 1D and L-carvone. The samples (about $250 \mathrm{mg}$ ) based on L-amino acids exhibit separation ee values of $\mathbf{1 L}, \mathbf{2} \mathbf{L}$ and $\mathbf{3 L}$ are $18.6 \%, 43.2 \%$ and $25.8 \%$, respectively. The largest separation ability of $\mathbf{2 L}$ may be attributed to the $-\mathrm{OH}$ groups, which promote the interaction between $2 \mathbf{L}$ and carvone.

\section{Conclusions}

In summary, we first constructed a series of homochiral ZMOFs with ABW topology by employing enantiopure amino acids with tetrazolate ligands. These materials show permanent 
microporosity and potential enantioselective recognition ability. This work reveals the versatile building strategy of zeolite analogs and opens a new approach toward the synthesis of homochiral ZMOFs by employing natural amino acids.

\section{Acknowledgements}

We thank the support for this work from NSFC (21425102, 21521061 and 21573236).

\section{Notes and references}

1 (a) M. Eddaoudi, D. F. Sava, J. F. Eubank, K. Adil and V. Guillerm, Chem. Soc. Rev., 2015, 44, 228; (b) L. Sun, H. Xing, Z. Liang, J. Yu and R. Xu, Chem. Commun., 2013, 49, 11155.

2 (a) T. Wu, X. Bu, J. Zhang and P. Feng, Chem. Mater., 2008, 20, 7377; (b) J.-P. Zhang, Y.-B. Zhang, J.-B. Lin and X.-M. Chen, Chem. Rev., 2012, 112, 1001; (c) Y. Liu, V. C. Kravtsov, R. Larsen and M. Eddaoudi, Chem. Commun., 2006, 1488.

3 (a) H.-X. Zhang, M. Liu, T. Wen and J. Zhang, Coord. Chem. Rev., 2016, 307, 255; (b) X.-C. Huang, Y.-Y. Lin, J. P. Zhang and X.-M. Chen, Angew. Chem., Int. Ed., 2006, 45, 1557.

4 (a) J. Zhang, T. Wu, C. Zhou, S. Chen, P. Feng and X. Bu, Angew. Chem., Int. Ed., 2009, 48, 2542; (b) J.-P. Zhang, A.-X. Zhu, R.-B. Lin, X.-L. Qi and X.-M. Chen, Adv. Mater., 2011, 23, 1268; (c) T. Wu, J. Zhang, C. Zhou, L. Wang, X. Bu and P. Feng, J. Am. Chem. Soc., 2009, 131, 6111; (d) R. Banerjee, H. Furukawa, D. Britt, C. Knobler, M. O'Keeffe and O. M. Yaghi, J. Am. Chem. Soc., 2009, 131, 3875.

5 (a) R. Banerjee, A. Phan, B. Wang, C. Knobler, H. Furukawa, M. O'Keeffe and O. M. Yaghi, Science, 2008, 319, 939; (b) B. Wang, A. P. Côté, H. Furukawa, M. O'Keeffe and O. M. Yaghi, Nature, 2008, 453, 207; (c) A. Phan, C. Doonan, F. J. Uribe-Romo, C. B. Knobler, M. O'keeffe and O. M. Yaghi, Acc. Chem. Res., 2009, 43, 58.
6 (a) F. Wang, H.-R. Fu, Y. Kang and J. Zhang, Chem. Commun., 2014, 50, 12065; (b) F. Wang, H.-R. Fu and J. Zhang, Cryst. Growth Des., 2015, 15, 1568; (c) F. Wang, Y.-H. Tang and J. Zhang, Inorg. Chem., 2015, 54, 11064; (d) Y.-H. Tang, F. Wang, J.-X. Liu and J. Zhang, Chem. Commun., 2016, 52, 5625; (e) M.-Y. Li, F. Wang and J. Zhang, Cryst. Growth Des., 2016, 16, 3063.

7 (a) T. Panda, P. Pachfule, Y. Chen, J. Jiang and R. Banerjee, Chem. Commun., 2011, 47, 2011; (b) S. Xiong, Y. Gong, H. Wang, H. Wang, Q. Liu, M. Gu, X. Wang, B. Chen and Z. Wang, Chem. Commun., 2014, 50, 12101; (c) S. Xiong, Q. Liu, Q. Wang, W. Li, Y. Tang, X. Wang, S. Hu and B. Chen, J. Mater. Chem. A, 2015, 3, 10747.

8 (a) Y. Liu, W. Xuan and Y. Cui, Adv. Mater., 2010, 22, 411; (b) J. S. Zhao, H. W. Li, Y. Z. Han, R. Li, X. S. Ding, X. Feng and B. Wang, J. Mater. Chem. A, 2015, 3, 12145; (c) M. C. Das, Q. Guo, Y. He, J. Kim, C.-G. Zhao, K. Hong, S. Xiang, Z. Zhang, K. Mark Thomas, R. Krishna and B. Chen, J. Am. Chem. Soc., 2012, 134, 8703.

9 (a) D. B. Dang, P. Y. Wu, C. He, Z. Xie and C. Y. Duan, J. Am. Chem. Soc., 2010, 132, 14321; (b) M. M. Wanderley, C. Wang, C.-D. Wu and W. Lin, J. Am. Chem. Soc., 2012, 134, 9050; (c) Z.-X. Xu, L. Liu and J. Zhang, Inorg. Chem., 2016, 55, 6355.

10 (a) R. Vaidhyanathan, D. Bradshaw, J.-N. Rebilly, J. P. Barrio, J. A. Gould, N. G. Berry and M. J. Rosseinsky, Angew. Chem., Int. Ed., 2006, 45, 6495; (b) M. Wang, M.-H. Xie, C.-D. Wu and Y.-G. Wang, Chem. Commun., 2009, 2396.

11 E. Yang, L. Wang, F. Wang, Q. Lin, Y. Kang and J. Zhang, Inorg. Chem., 2014, 53, 10027.

12 G. M. Sheldrick, Acta Crystallogr., Sect. A: Found. Crystallogr., 2008, 64, 112.

13 R. E. Marsh, Acta Crystallogr., Sect. B: Struct. Sci., 1999, 55, 931.

14 P. Van der Sluis and A. L. Spek, Acta Crystallogr., Sect. A: Found. Crystallogr., 1990, 46, 194. 